\title{
The Present and Future of Commuting - report from the Telč Seminar 2019
}

\section{Martin Kvizda ${ }^{1}$}

In November 2019, a traditional discussion seminar was held for the fourteenth time at the University Center of Masaryk University in Telč, this time entitled "The Present and Future of Commuting Relations". The seminar was organized by the Institute for Transport Economics, Geography and Politics (ITREGEP - Joint Research Institute of Masaryk University in Brno and Charles University in Prague) within the project "New Mobility - High-Speed Transport Systems and Population Transport Behavior" (reg. No.: CZ.02.1.01 / 0.0 / 0.0 / 16_026 / 0008430, Operational Program Research, Development and Education).

The aim of the seminar was to discuss the economic, social, and spatial aspects of the daily mobility of the population, with an emphasis on transport policy and planning. The seminar program and the main questions and issues discussed were adapted to this: monitoring and analysis of traffic flows in regions; transport links between metropolises and their hinterlands; analysis of daily rhythms in the context of regional transport services and the provision of transport services for the needs of regional mobility.

The seminar was prepared and chaired by the Program Committee consisting of: M. Kvizda, D. Seidenglanz, Z. Tomeš (Masaryk University in Brno) and T. Nigrin (Charles University in Prague). The seminar was attended by invited guests from the academic sphere (Masaryk University in Brno, Charles University in Prague, Comenius University in Bratislava, University of South Bohemia in České Budějovice and Žilina University in Žilina were all represented), furthermore regional and local government (Vysočina Region, South Moravian Region, Zlín Region and Statutory City of Brno), from regional transport coordinators (POVED, s.r.o. Plzeň and KORDIS JMK, a.s. Brno), from carriers (Arriva Transport ČR, a.s., České dráhy, a.s. and Železničná spoločnost' Slovensko a.s.) and representatives of other stakeholders (OLTIS Group, s.r.o., Siemens Mobility, a.s. and the Prague Institute of Planning and Development).

Ondřej Špetík (Masaryk University) opened the first presentation and discussion block with a presentation entitled "Does the tendering process reflect the commuting relations?", in which he summarized the findings of expert controlled interviews with representatives of all Czech regional public transport customers. The following discussion, which focused on the use of data sources for the purposes of awarding public tenders for the provision of subsidized transport services, revealed that only five of the fourteen Czech regional customers use at least some kind of empirical data sets on transport. This problem is related, inter alia, to the fact that individual orders of

\footnotetext{
${ }^{1}$ Faculty of Economics and Administration, Masaryk University, Lipová 41a, Brno, Czech Republic, kvizda@econ.muni.cz
}

(C) 2020 by the authors; licensee Review of Economic Perspectives / Národohospodárský obzor, Masaryk University, Faculty of Economics and Administration, Brno, Czech Republic. This article is an open access article distributed under the terms and conditions of the Creative Commons Attribution 3.0 license, Attribution - Non Commercial - No Derivatives. 
regional transport are not supra-regional coordinated (although 1/3 of the outputs are subsidized by the state), which leads to an increasingly frequent breakdown of transport links on the border of regions. An interesting fact, which was also mentioned in the discussion and which is to some extent contrary to the previous thesis, is that in recent years some regions have started to order connections outside their administrative territory as well, namely the South Moravian Region. It may seem that this way of ordering is at least partial and, at the same time, a pragmatic, but not systemic, solution of the ongoing fragmentation of transport systems.

Miroslav Marada (Charles University) and Marcel Horňák (Comenius University) presented another presentation on the theme of "Commuting relations and daily rhythms - empirical study", focusing on the geography of time and spatial interaction. The presenters dealt with the question of the real definition of public transport service, in particular, by establishing requirements for the provision of transport services: whether it should be a blanket standard in the region irrespective of actual demand and utilization rates, or simply providing a minimum standard for persons without other transport options, with additional transport layers being demand-driven. In this context, they also expressed the opinion that real commuting links are being modified in connection with metropolitanization processes, the attractiveness of weaker centers is decreasing, and especially in the case of strong centers such as Prague and Brno, the commuting distance is increasing significantly. The influence of Prague thus in some cases reaches to the border areas and undermines the integrity of the hinterlands of some weaker inter-regional centers (Hradec Králové, Liberec, Ústí nad Labem). These processes put pressure on the reorganization of regional integrated transport systems. The subject of discussion was also the applicability of empirical data for regional transport service planning; the discussion showed that the degree of inaccuracy of empirical data is relatively high and leads to a significant error rate of the subsequent analysis. Many customers thus make greater use of their local knowledge, the direct requirements of individual municipalities, and the experience of carriers (drivers). Unfortunately, the use of the carrier's own data is not ideal either: in fact, information on up to a third of the journeys made are missing; data is lost, in particular, in the context of integrated transport system zone tickets.

This was followed by a block in which Václav Rederer, Jakub Chmelík and Jan Hrabáček (Czech Railways) started a discussion on the topic "Analysis of commuting relations from the carrier's point of view". The authors focused mainly on the question of what is a (regular) commute and also emphasized the fact that the share of leisure trips on the longer train routes is increasing significantly. The main aim of the paper, however, was to introduce changes in typical distances from which they regularly commute by train to individual regional cities. The analysis revealed some interesting connections: the distance of commuting depends, of course, on the size and attractiveness of the destination and also on the monocentric or polycentric arrangement of the dealt with the region, but it is also significantly influenced by the quality of the railway transport supply (train frequency and schedule, infrastructure and speed, etc.). An interesting finding was the impact of the quality of the vehicle fleet on demand for transport services: on most of the affected ČD lines there were significant increases in passengers after the introduction of modern low-floor vehicles equipped with air conditioning, Wi-Fi, etc.; however, this effect also has its limits on routes where the 
potential demand is weak and cannot generate an influx of new passengers (for example in Vysočina).

Květoslav Havlík (KORDIS) also continued in the presentation and discussion on the topic "Analysis of commuting relations from customers' point of view". A significant finding was the gradual disintegration of space-time routines among important groups of people, especially students and employees: the change in the scope and way of organizing lessons, the possibility of using sickdays, homeoffices, moving working hours etc. weakens the regularity of transport, the intensity and timing of traffic peaks and saddles, thus reducing the predictability of busy connections. He considers the own data of carriers and transport service subscribers as the best usable empirical data, especially for city or small area traffic planning. However, this data also encounters problems with the census of passengers; information from the sale of electronic tickets is unusable as it accounts for only about $1 \%$ of all tickets. Therefore, he accepts that, especially for the monitoring of long-distance traffic links, the big signal data of mobile operators are suitable. At the same time, however, he pointed out that individual operators use different methodologies in several consecutive surveys and the resulting information varies a lot. In border regions, the estimation of traffic flows using mobile data is limited by the impossibility of using foreign operators' SIM cards, mainly due to different GDPR. To refine the census, a so-called calibration census is often ordered to verify the validity of the main research. The introduction of a route by trial is a useful but very costly method of planning the optimal transport service. However, it takes at least 1-2 years for passengers to find and use the domestic line, and for cross-border lines, it takes up to 3 years.

An empirical study and the possibility of using data files in the "Analysis of commuting in the background of metropoles" was presented by Daniel Seidenglanz and Vilém Pařil (Masaryk University). Although the regularity of journeys has declined in recent decades, we can still say with some generalization that commuting to and from work continues to be a relatively regular, rationalized, and routine movement. From the perspective of transport policies and transport service providers, it therefore still represents a key type of mobility for which the desired change in transport mode can be targeted. Based on the case studies presented (Brno and its hinterland, the Benešov region), the choice of public transport and, of course, the railway is significantly dependent on the quality of available infrastructure and the offer of a well-arranged timetable. Its use can also be supported by other incentives, such as the promotion of a combination of car and public transport through park \& ride systems. However, an important factor influencing the choice of means of transport is the lifestyle or mobility style, which is strongly manifested e.g., in suburban fringes of big cities. The construction of high-speed lines may be another step in improving the quality of public rail transport in the Czech Republic. Therefore, the hypothetical question of what their commissioning would cause in commuting to work at the inter-metropolitan level was addressed. An analysis comparing time investment on the one hand and the gradual increase in wages on the other shows the highest attractiveness of Prague. Compared to it, Brno reaches about one-third the value and Ostrava and Pilsen do not fulfill the role of attractive centers too much based on the performed analysis. Subsequent discussions have shown that the regional impact of high-speed lines can be very diverse, in addition to strengthening regional centers, they can also weaken them and strengthen their 
dependence on major metropolises. The outcome then depends on both their economic and regional strength and a number of other factors, including the scale of analysis.

The first conference day was concluded by a presentation by Ondřej Špaček (CETraffic) on the topic "Binding mobility analysis to other development topics". Among other things, the presentation focused on the comparison of the validity of different data sets, which can no longer be objectively assessed. The relevance of certain data sets is either higher or lower in relation to the purpose of their use, but there is no such thing as objective reality - always just another set of certain data. The basic problem of the sufficient granularity of spatio-temporal data is caused by the frequency of a phone logging into the network, which happens at least once every half an hour in idle times, but much more frequently when using the device. The collection and thus the validity of the data are also influenced by the operator's infrastructure; paradoxically, new networks (4G, LTE, etc.) make it difficult to measure and collect valid data, as new technologies are leading, among other things, to the possession of multiple sim cards, their placement in vehicles, security devices, GPS, etc. Thus, when data files are used in research, the correct calibration of data is increasingly important.

The seminar agenda included a panel discussion on the second day of the meeting, which was moderated by Martin Kvizda on the topic "Mobility in 50 years - Where we are and where we will go?". The panelists included Marcela Benediktová (POVED Pilsen, regional coordinator of public transport), Marcel Horňák (Faculty of Science, Comenius University in Bratislava, transport geographer), Martin Kendra (Faculty of Operation and Economics of Transport and Communications, University of Žilina, transport engineer), Pavel Szobi ( Charles University Prague, historian) and Lukáš Tittl (IPR Prague, traffic engineer). In the first block of the discussion entitled "Having One's Own Car as a Thing of the Past", the discussion focused on transforming mobility and the relationship with vehicles in history. Of course, transport technology has been changing over time, from walking to using animals, introducing public transport to developing individual car transport - ownership of a means of transport has always been a symbol of property, freedom, and expression of owner status. At the same time, the dominant transport technology strongly determines the way of life, the form of settlements and settlement system, the arrangement of spatial socio-economic links, and also the economic structure of the sector. In addition to the available transport technology, the form of ownership of the means of transport is also changing, so there is already a social stratum that does not need to own a car but only needs to utilize transport (instead of car ownership, purely its availability is becoming important). Cars may soon be replaced by smartphones as a status symbol. This change, i.e. the development of a carsharing system, along with the technological changes to cars (autonomous driving, driving, electromobility, and many others), as well as the improvement of the public transport offer, has the potential to significantly modify the organization and security of transport services.

In the second block, "Cars will be different, but individuality will remain," this issue was further discussed by the discussion participants. Especially for young, educated, and urban populations growing up in times of shared services and accustomed to their accessibility via the Internet, changing their relationship to cars is not very complicated and likely to occur. In doing so, it is necessary to abandon the current perception of the car as a status symbol and focus primarily on the efficient functioning of the transport 
system as a whole. In certain segments of the population it is even cool or trendy not to own a car and to use public transport or shared transport. A major problem of the system of transport sharing is the issue of peak demand (weekends, holidays, morning and evening rush hour), when there may be an excess demand for these services, as well as space availability. In the urban environment, the provision of services is logistically resolvable, but in rural areas with a low population and population density, this can be complicated (a more general issue of spatial justice). The question also arises whether these services should be included in the public interest in the future in order to finance their availability from public sources. On the other hand, unused or over-capacity public transport could be replaced in some areas. The question remains whether the organization of individual public transport based on autonomous vehicles can simply be provided by the market, or it will be necessary to subsidize these services to a certain extent from public sources and organize their distribution. The way to reduce the negatively perceived and negative externalities of individual car transport can be by increasing its price or by regulating the demand for mobility.

The third part of the discussion entitled "We will be older, richer, urban and ecological" elaborated on these issues in the context of expected demographic and economic development. The discussion participants pointed out that we are addressing these problems at a time when the rate of individual mobility is the highest in history and at a time when people are used to providing it individually and flexibly through their own cars in the long term - these facts cannot be overlooked when considering the future design of the transport system. Nor can we ignore the current aging trends, which also have the potential to strongly modify transport demand. In particular, it is necessary to monitor the development in the trend of housing location and the temporal and spatial distribution of work and leisure activities; the demand for transport may thus have a completely different structure in the future. It is also worth noting that we live in a time of relatively cheap transport services not only in the Czech context. Relative transport prices and, hence, demand for transport may change significantly in the near future.

In the last block "Information sources for traffic prediction", the discussion focused on how and on what basis to predict transport demand in a relatively turbulent time. In connection with the presentation of the possibility of using signaling data of mobile operators, their real usability was discussed. The discussion participants agreed that data on mobility change is important, not just its actual size. Signaling data may be useful for this, but it is necessary to supplement it with data from which it is possible to trace the motive of current mobility and thus predict future changes. Unfortunately, in the Czech context, the approach to transport planning based solely on quantifying existing transport demand prevails. Changing such an approach in society is a major challenge for the Telč Group and its future seminars. 